\title{
Typical Failure Mode Analysis of Embankment during Construction
}

\author{
Binbin $\mathrm{XU}^{1, \mathrm{a}}$ and Wei $\mathrm{SI}^{2, \mathrm{~b}}$ \\ ${ }^{1}$ Tianjin Port Engineering Institute, Key Lab. of Geotechnical Engineering of Tianjin, Key Lab. of \\ Geotechnical Engineering, Ministry of Communication, Tianjin, 300222, China \\ 2 Tianjin Port Engineering Institute, Key Lab. of Geotechnical Engineering of Tianjin, Key Lab. of \\ Geotechnical Engineering, Ministry of Communication, Tianjin, 300222, China \\ a xubinbin@tpei.com.cn, b siwei@tpei.com.cn
}

\section{Keywords: Numerical analysis, Failure mode, Slide surface, Plastic damage point}

Abstract. In order to help the engineer to understand the variation inside the ground before and after the failure of the embankment, to avoid the accident, the surcharge preloading with plastic vertical drains is carried out numerically. The loading rate is accelerated artificially to analyze the variation of the settlement, horizontal displacement, excess pore pressure before and after the failure of the embankment. The results can be used to analyze the measured datum to evaluate the stability of the embankment of the slope.

\section{Background}

The surcharge preloading method has been widely used in the improvement of soft ground to increase its bearing capacity [1-4]. Usually it is used accompany with the plastic vertical drains so that the excess pore pressure caused by embankment load can dissipate in time. If the loading rate is too fast or the drainage passage is not effective, there is a risk that the embankment may fail. In practical engineering, the monitoring instruments are adopted to get measured datum to evaluate the state of the embankment. However, due to the shortage of datum of embankment failure, it is difficult the judge the measured datum. Therefore, numerical calculations are carried out by accelerating the loading rate so that the failure of the embankment occurs during the construction to help the engineer understand the variation of measured datum before and after the failure.

\section{Calculation Conditions}

Figure 1 demonstrates the mesh information for the calculation. The solid element is used to represent the embankment and total load of the embankment is around $80 \mathrm{kPa}$. The normal constraints are applied on the four side surfaces and the fixed constraints are applied on the bottom surface.

The ground is composed of 6 layers and the corresponding parameters are listed in Table 1 . In the calculation, Mohr-column model is used.

For the surcharge preloading, the embankment is constructed layer by layer and the height of each layer is $1 \mathrm{~m}$. Due to the poor physical and mechanical property of the ground, the surcharge preloading method with plastic vertical drains is adopted to improve the soft ground. In this simulation, the drainage surface is used to represent the plastic vertical drains and the interval space is $2 \mathrm{~m}$. During the surcharge preloading, the rate of adding embankment is usually very slow so that the excess pore pressure can dissipate in time and the bearing capacity of the ground can be increased. However, in this calculation in order to analyze the failure mode of the embankment, the loading rate is accelerated artificially and the time interval between two layers is set to be $10 \mathrm{~d}$. 


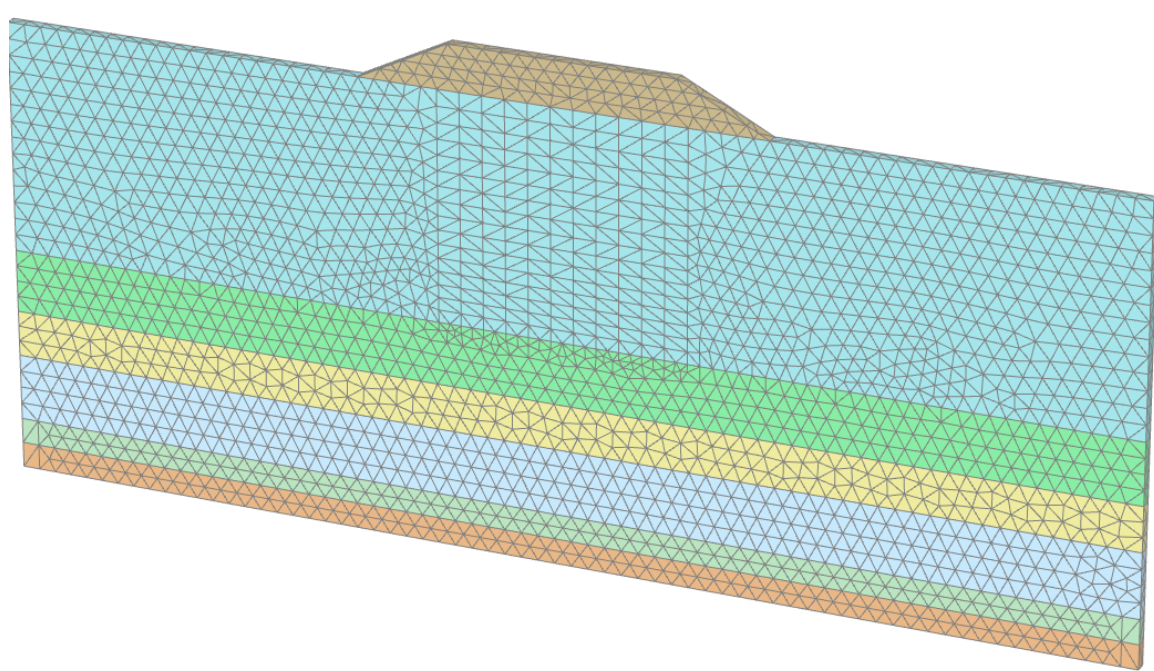

Figure 1 Mesh information

Table 1 Soil Parameters

\begin{tabular}{|c|c|c|c|c|c|c|c|}
\hline NO. & Soil & $\begin{array}{c}\text { Bulk } \\
\text { density } \\
\left(\mathrm{kN} / \mathrm{m}^{3}\right)\end{array}$ & $\begin{array}{c}\text { Young's } \\
\text { Modulus } \\
(\mathrm{kPa})\end{array}$ & $\begin{array}{l}\text { Poisson's } \\
\text { ratio }\end{array}$ & $\begin{array}{l}\text { Friction } \\
\text { angle }\left(^{\circ}\right)\end{array}$ & $\begin{array}{l}\text { Cohesive } \\
\text { strength } \\
(\mathrm{kPa})\end{array}$ & $\begin{array}{l}\text { Permeability } \\
(\mathrm{m} / \mathrm{d})\end{array}$ \\
\hline 1 & Mud & 16.4 & 1241 & 0.3 & 12.3 & 6.8 & $1.1 \mathrm{e}-4$ \\
\hline 2 & $\begin{array}{l}\text { Silty } \\
\text { clay }\end{array}$ & 19.8 & 3982 & 0.3 & 14.4 & 25.4 & $5.2 \mathrm{e}-4$ \\
\hline 3 & $\begin{array}{l}\text { Mucky } \\
\text { silty clay }\end{array}$ & 18.7 & 3098 & 0.3 & 18.0 & 14.5 & $1.2 \mathrm{e}-4$ \\
\hline 4 & Silt & 20.0 & 5690 & 0.3 & 30.2 & 12.0 & $5.7 e-3$ \\
\hline 5 & $\begin{array}{l}\text { Silty } \\
\text { clay }\end{array}$ & 19.6 & 3216 & 0.3 & 9.6 & 27.0 & $3.6 e-5$ \\
\hline 6 & Clay & 20.2 & 5478 & 0.3 & 28.5 & 24.3 & $3.6 e-5$ \\
\hline
\end{tabular}

\section{Typical Failure Characteristics}

Variation of Settlement. The settlements at the ground surface after 3rd and 4th embankment layer are shown in Figure 2. As can be seen, after 3rd layer, the maximum settlement still locates at the center of the embankment and there is only slight upheave at two side of the embankment, which follows the same tendency at the first and second layer. The maximum settlement and the maximum upheave after 3 rd layer are $69.7 \mathrm{~cm}$ and $14.0 \mathrm{~cm}$ respectively. However, after the 4 th layer is added there is significant variation both in the shape and magnitude of the settlement. Obvious settlement and upheave appear near the toe of the embankment. The maximum settlement and the maximum upheave become $142.4 \mathrm{~cm}$ and $97.7 \mathrm{~cm}$, which increases $104 \%$ and $598 \%$ respectively compared with the previous stage. 


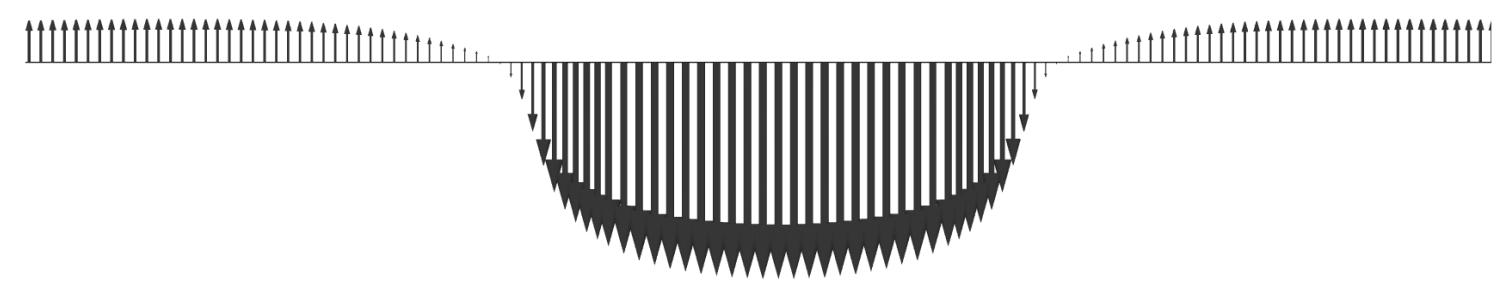

(1) Vertical deformation at the ground surface after third layer

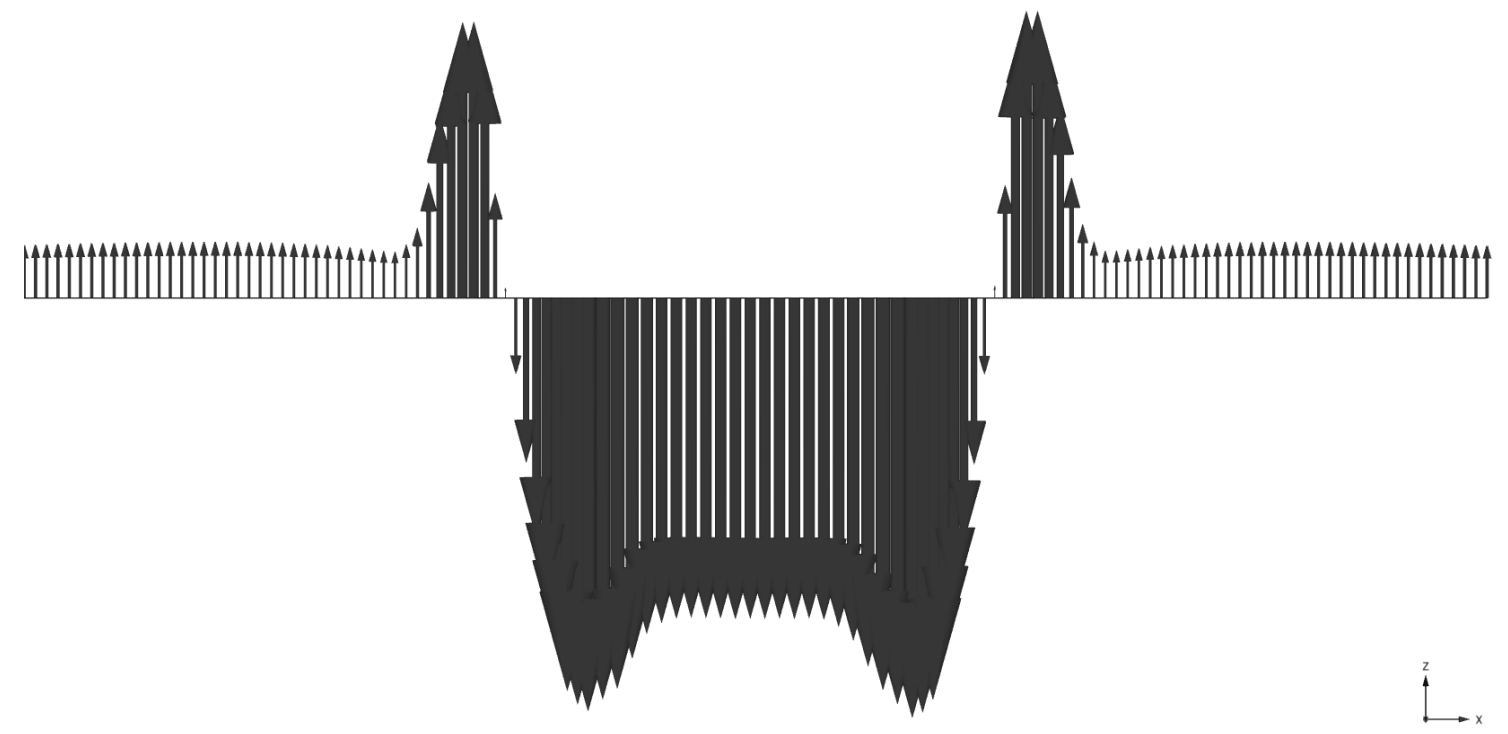

(2) Vertical deformation at the ground surface after fourth layer

Figure 2 Variation of vertical deformation before/after failure

Variation of Horizontal Displacement. The horizontal displacement at the toe of the embankment at two stages is shown in Figure 3, which can be regarded as an inclinometer. As can be seen, the maximum horizontal displacement appears at the ground surface and the direction is toward the outside of the embankment. After the third layer, the maximum value is $20.3 \mathrm{~cm}$ but the value becomes $66.3 \mathrm{~cm}$ after the fourth layer is added. The extent of increase is over $227 \%$, which also indicates that there is dramatic variation inside the ground at the time of failure.

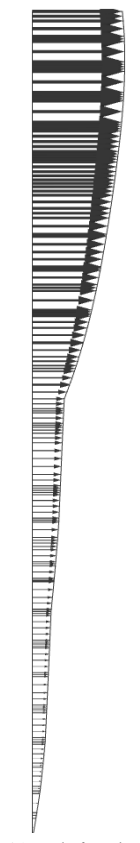

(1) third layer

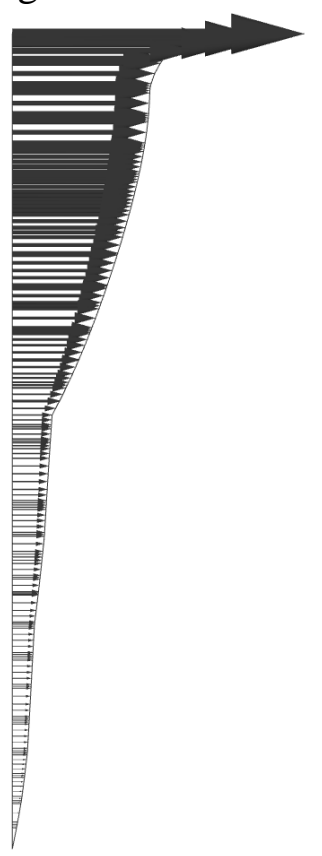

(2) fourth layer

Figure 3 Distribution of horizontal displacement along depth at the boundary at two stages 
Variation of Plastic Damage Points. In Plaxis, the plastic damage point can be determined and Figure 4 shows the distribution of plastic damage point inside the ground. Limited to the space, the plastic damage points begin to occur inside the ground even after the construction of the first layer and then the area gradually increases. After the third layer, there have been plenty of plastic damage points inside the ground, but there are no connected plastic points to form the sliding surface inside the ground. However, after the construction of fourth layer, there is obvious X-shape plastic damage point inside the ground, which can be interpreted as the shear band inside the ground.

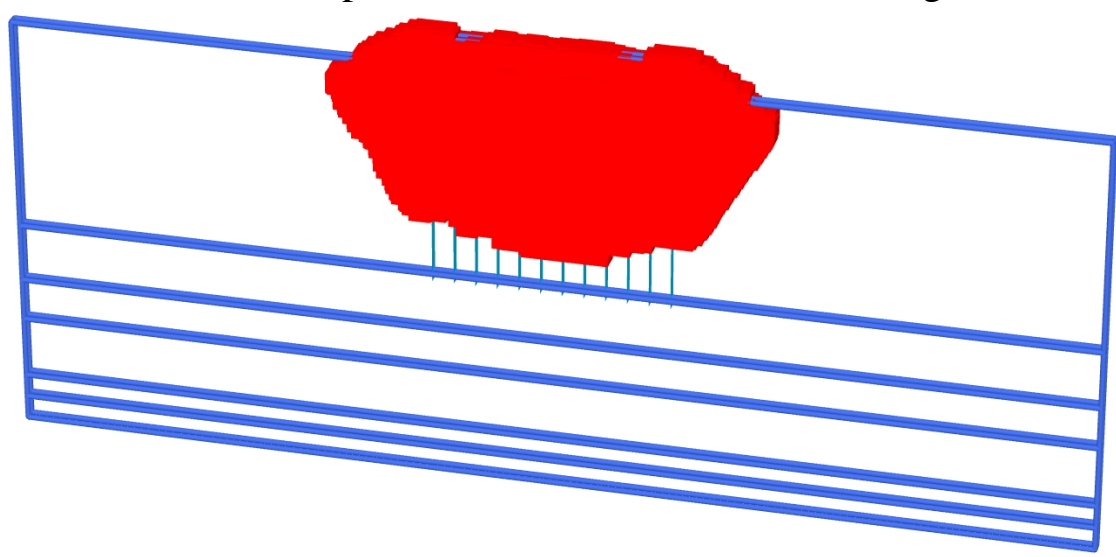

(1) third layer

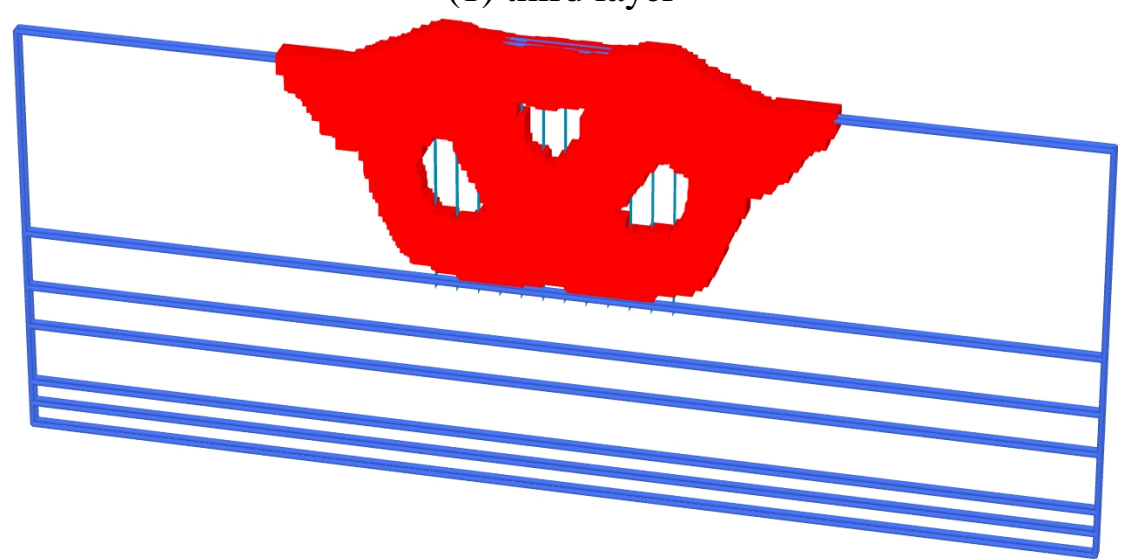

(2) fourth layer

Figure 4 Distribution of plastic damage point inside the ground at two stages

\section{Conclusions}

In order to help the engineer to understand the variation inside the ground before and after the failure of the embankment, to avoid the accident, the surcharge preloading with plastic vertical drains is carried out numerically. There is significant variation for the settlement, horizontal displacement and plastic damage points. The conclusions are as follows:

1) The maximum settlement and the maximum upheave become $142.4 \mathrm{~cm}$ and $97.7 \mathrm{~cm}$, which increases $104 \%$ and $598 \%$ respectively compared with the previous stage.

2) The maximum horizontal displacement becomes $66.3 \mathrm{~cm}$ after the fourth layer is added, which is over $227 \%$ higher than that in the previous stage.

3) After the construction of fourth layer, there is obvious X-shape plastic damage point inside the ground and the slide surface in the depth ground begins to occur, which can be interpreted as the shear band inside the ground. 


\section{References}

[1] Chai J.C., Miura N., Sakajo S. and Bergado D., Japan Soc. Soil Mech. and Found. Eng., 1995, 35(4): 49-61.

[2] Indraratna B. and Redana I. W., J. Geotech. and Geoenviron. Engrg. ASCE. 1997(5): 474-478.

[3] Hird C. C., Pyrah I. C. and Russel D., Geotechnique, 1992(4):499-511.

[4] Mesri G. and Khan A.Q., J. Geotech. Geoenviron. Eng., 2012 138: 680-689. 